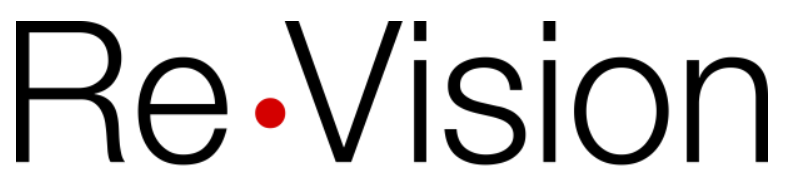

$\overline{\text { UNIVERSITY }}$

of GUELPH

The Centre for Art and Social Justice

\title{
Healthcare providers' engagement with eating disorder recovery narratives: Opening to complexity and diversity
}

Andrea LaMarre

Massey University

Carla Rice

University of Guelph

This is a post-peer-review, pre-copyedit version of an article published in Medical Humanities. The final authenticated version is available online at: http://dx.doi.org/10.1136/medhum-2019-011723

Recommended citation:

LaMarre, A., \& Rice, C. (2020). Healthcare providers engagement with eating disorder recovery narratives: Opening to complexity and diversity. Medical Humanities. http://dx.doi.org/10.1136/medhum$\underline{2019-011723}$ 


\section{Healthcare Providers' Engagement with Eating Disorder Recovery Narratives: Opening to Complexity and Diversity}

\section{Abstract}

Interdisciplinary healthcare providers (HCPs) receive only minimal training in identifying, referring for, and treating eating disorders and may feel ill-prepared to manage them. There is a need for brief interventions that prepare HCPs for work with people with eating disorders, particularly when they do not fit stereotypes about who might experience an eating disorder. One method for enacting brief interventions that make change in this realm is using digital stories (short films) to generate awareness and knowledge. In this article, we discuss the results of a pilot study exploring the impact of viewing digital stories created by people in eating disorder recovery and their supporters on an interdisciplinary group of HCPs. We showed five stories to $22 \mathrm{HCPs}$ who filled out qualitative pre and post questionnaires about their experiences of viewing the films and how they conceptualized recovery. Providers found the stories evocative; the stories appear to have complexified their perspectives on recovery. HCPs desired more diverse, detailed, and lengthy stories, indicating that pursuing digital storytelling for healthcare provider education and awareness may hold promise. Through centring the voices of people with eating disorders and in recovery, digital stories may also provide new ways of talking about recovery that open up possibilities for embracing difference. 


\section{Keywords}

healthcare education, mental health care, arts in health, film

Healthcare providers (HCPs) receive little training in how to identify, make decisions around, and treat eating disorders ${ }^{-}$. It is rare to find medical schools that include built-in eating disorders training opportunities and many medical programs offer fewer than five hours of eating-disorder-related curriculum². Medical residencies do not always offer rotations in eating disorders, and when they do, these rotations tend to be

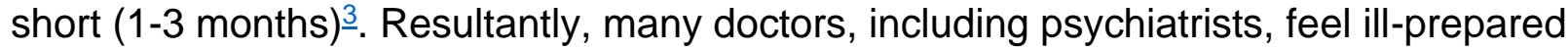
for the realities of screening for, assessing the medical risks of, managing on an outpatient basis, and distinguishing between eating disorders 4 . Doctors are not the only healthcare professionals who lack eating-disorder-specific training opportunities; physiotherapists, nurses, occupational therapists, and other multi-disciplinary HCPs similarly lack training, which can impact their ability to help people with eating disorders.

The lack of training for healthcare professionals impacts those with eating disorders. Eating disorders are often misunderstood and wrongly interpreted to be

\footnotetext{
${ }^{1}$ Laura Girz, Adele Lafrance Robinson \& Carole Tessier, 2014 "Is the next generation of physicians adequately prepared to diagnose and treat eating disorders in children and adolescents?"; Fauzia Mahr, Pantea Farahmand, Edward O. Bixler, Ronald E. Domen, Eileen M. Moser, Tania Nadeem, Rachel L. Levine \& Katherine A. Halmi, 2015 "A national survey of eating disorder training"

2 Laura Girz, Adele Lafrance Robinson \& Carole Tessier, 2014 "Is the next generation of physicians adequately prepared to diagnose and treat eating disorders in children and adolescents?" ${ }^{3}$ Fauzia Mahr, Pantea Farahmand, Edward O. Bixler, Ronald E. Domen, Eileen M. Moser, Tania Nadeem, Rachel L. Levine \& Katherine A. Halmi, 2015 "A national survey of eating disorder training" 4 William R. Jones, Saeideh Saeidi \& John F. Morgan, 2013 "Knowledge and attitudes of psychiatrists towards eating disorders; Meris Williams \& Pierre Leichner, 2006 "More training needed in eating disorders: A time cohort comparison study of Canadian psychiatry residents"
} 
issues of vanity and choice ${ }^{5}$. There are strongly-ingrained stereotypes about who might experience an eating disorder; despite being illustrated as fallacious, pervasive myths circulate that suggest that eating disorders "only happen" to thin, young, white, heterosexual, cis-gender women in thin bodies ${ }^{6}$. These myths have consequences for access to support and understanding for those experiencing distress. For instance, Lebow, Sim and Kransdorf $(2015)^{\underline{7}}$ have illustrated how people in larger bodies are less likely to be recognized as having eating disorders, leading to delays in treatment and perhaps exacerbation of illness. Ethnic minority women also face significant barriers to treatment, including financial barriers, concerns about cultural competence of therapists, fear of being labelled, and more ${ }^{8}$. Lacking recognition of the existence of eating disorders amongst people who are not white is an issue in both medical and nonmedical settings; eating disorders have historically $\underline{9}$ and continue to be $\frac{10}{10}$ more commonly recognized amongst white women than other groups.

\section{Eating Disorder Recovery}

\footnotetext{
${ }^{5}$ Arthur Crisp, Michael G. Gelder, Susannah Rix, Howard I. Meltzer \& \& Olwyn J. Rowlands, 2000 "Stigmatisation of people with mental illnesses"; James P. Roehrig \& Carmen P. McLean, 2010 "A comparison of stigma toward eating disorders versus depression"

${ }^{6}$ Susan Bordo, 2009 "Not just "a white girl's thing": The changing face of food and body image problems"; Rebecca Jones \& Helen Malson, 2013 "A critical exploration of lesbian perspectives on eating disorders"; Carla Rice, 2014 Becoming women: The embodied self in image culture 7 Jocelyn Lebow, Leslie A. Sim \& Lisa N. Kransdorf, 2015. "Prevalence of a history of overweight and obesity in adolescents with restrictive eating disorders"

${ }^{8}$ Fary M. Cachelin, Ramona Rebeck, Catherine Veisel \& Ruth H. Striegel-Moore, 2001 "Barriers to treatment for eating disorders among ethnically diverse women"

${ }^{9}$ Kathryn H. Gordon, Marisol Perez \& Thomas E. Joiner, 2002 "The impact of racial stereotypes on eating disorder recognition"

10 Sarmila Sinha \& Nasir Warfa, 2013 "Treatment of eating disorders among ethnic minorities in Western settings: A systematic review"
} 
Even when people present to clinicians with eating disorders, are diagnosed, and receive treatment, the "end point" of treatment can remain ephemeral. Perspectives on recovery vary within the eating disorders field; in general, recovery is thought to be comprised of measurable changes in symptomatology alongside other psychosocial improvements, though there is disagreement about which psychosocial variables are most important in demonstrating recovery 11 . Until relatively recently, a majority of studies exploring treatment outcomes focused on whether the individual had stopped engaging in problem behaviours such as binging, purging, and restriction $\frac{12}{2}$. In recoveryoriented studies, other factors explored have included well-being ${ }^{13}$, social factors $\frac{14}{4}$, and coping skills $\underline{15}$. Recent studies have highlighted the need to examine quality of life as a factor in recovery $\underline{16}$ and how self-reported recovery can differ significantly from "objective" measures 17 .

\footnotetext{
${ }^{11}$ Bardone-Cone et al., 2010 "Defining recovery from an eating disorder: Conceptualization, validation, and examination of psychosocial functioning and psychiatric comorbidity."

12 Bardone-Cone et al. 2018 "An overview of conceptualizations of eating disorder recovery, recent findings, and future directions"

${ }^{13}$ Ackard, Richter, Egan \& Cronemeyer 2014 "What does remission tell us about women with eating disorders? Investigating applications of various remission definitions and their associations with quality of life"

${ }^{14}$ Kordy et al., 2002 "Remission, recovery, relapse, and recurrence in eating disorders: Conceptualization and illustration of a validation strategy";

${ }^{15}$ Fitzsimmons \& Bardone-Cone, 2010 "Differences in coping across stages of recovery from an eating disorder"

${ }^{16}$ deVos et al., 2017 "Identifying fundamental criteria for eating disorder recovery: a systematic review and qualitative meta-analysis"

${ }^{17}$ Romano \& Ebener, 2019 "Disparities in psychological well-being based on subjective and objective eating disorder recovery statuses, and recovery status concordance"; Bardone-Cone et al., 2012 "Examining the match between assessed eating disorder recovery and subjective sense of recovery: Preliminary findings."; Slof-Op't Landt, Dingemans, Rivas \& van Furth, 2019 "Self-assessment of eating disorder recovery: Absence of eating disorder psychopathology is not essential."
} 
The notion that recovery is an agreed-upon state persists in outcomes literature, despite myriad different approaches to defining and understanding recovery $\underline{18}$. Inconsistencies in definitions and criteria used to determine "recovery" have led to disparate claims about the possibility of recovery and how that relates to different treatment modalities $\stackrel{19}{ }$. At present, we lack a consensus definition of recovery, though efforts toward such a definition are under way $\underline{20}$.

Implicating the contexts in which recovery takes place adds a wrinkle to carving out a definition of recovery-especially one based on symptom remission. People often "recover" into a society where routine restricting and excessive exercising, among other "health-focused" behaviours, are encouraged 21 . This can make recovery particularly challenging for those with eating disorders who do not fit stereotypes around what the bodies of people with eating disorders look like. HCPs are not immune to perpetuating societal stereotypes about what bodies fit $\underline{22}$ _and what bodies are fit. Limited training opportunities for HCPs on eating disorders collides with societal, research, and treatment confusions about what recovery "is" to create an urgent need for deep

\footnotetext{
${ }^{18}$ Bardone-Cone et al. 2018 "An overview of conceptualizations of eating disorder recovery, recent findings, and future directions"

${ }^{19}$ Bardone-Cone et al. 2018 "An overview of conceptualizations of eating disorder recovery, recent findings, and future directions"

20 Wade \& Lock, 2019 "Developing consensus on the definition of remission and recovery for research."; Bachner-Melman, Lev-Ari, Zohar \& Lev, 2018 "Can recovery from an eating disorder be measure? Toward a standardized questionnaire."

${ }^{21}$ LaMarre \& Rice, 2016 "Normal Eating Is Counter-Cultural: Embodied Experiences of Eating Disorder Recovery"

22 Foster et al., 2003, "Primary care physicians' attitudes about obesity and its treatment."; Korf \& KorfUzan, 2014, "Addressing weight bias and stigma in health care."
} 
exploration around matters of eating and bodies in the context of HCP training and professional development.

In other fields of mental health, patients have been involved in exploring what recovery means to them. Over the past decade, the "recovery model" has become more popular mental health care in the UK and other countries, including Canada $\underline{23}$. The recovery model holds that recovery is individual to the person in their context; when integrated into treatment, this manifests through the explicit integration of patient perspectives into the design of and goals for care ${ }^{24}$. Recovery is not just about "cure" or remission; in this model, recovery and care are interwoven with the challenges associated with being in a "patient" role, which can carry its own problems and often lead to something other than complete wellness $\underline{25}$. This perspective on recovery has been referred to as the "consumer/survivor movement," led as it has been by those who have experienced harm in treatment contexts that did not take into account their perspectives. This movement has not lacked detractors; some HCPs have resisted the integration of patients into program design processes because of fears around patients' voices becoming louder than those of clinicians $\underline{\underline{26}}$.

\footnotetext{
${ }^{23}$ Department of Health, 2012 Government response to the consultation: "Liberating the NHS: No decision about me, without me."; Lynda Tait \& Helen Lester, 2005 "Encouraging user involvement in mental health services"

24 William Anthony, 1993 Recovery from mental illness: The guiding vision of the mental health service system in the 1990s

25 Jennifer Poole, 2011 Behind the rhetoric: mental health recovery in Ontario.

${ }^{26}$ Nancy Tomes, 2006 "The patient as a policy Factor: A historical case study of the consumer/survivor movement in mental health"
} 
The very existence of the recovery movement invites one to pause and consider power in relation to definitions of recovery for all mental health concerns, including eating disorders. While there is a stated desire for patient-oriented care in eating disorder treatment $\underline{27}$, this desire has not always borne out in service design. Care practices remain entangled with power and the valuing of patient perspectives is limited $\underline{28}$ due largely to concerns around the dominance of "the eating disorder voice" $\underline{29}$. This may be at least in part due to the serious, often life-threatening nature of eating disorders. Further, the voices of those diagnosed are not always trusted; people with eating disorders are often described as denying the seriousness of their illness either due to anosognosia or through deliberate refusal to recognize their illness $\frac{30}{0}$. Studies demonstrate that those diagnosed with eating disorders differ in terms of whether or not they see their behaviours as positive or negative with those who see their behaviours, or see more of their behaviours, as negative being more motivated to make change 31 .

Regardless of their orientation toward their illness, surely there is room for supportive collaboration with people with eating disorders. While a recovery model

\footnotetext{
27 Berg, Hurley, McSherry \& Strange, 2002. Eating disorders: A patient-centered approach.

28 See Rebecca Lester, 2018 "Ground zero: Ontology, recognition, and the elusiveness of care in American eating disorders treatment" for a recent, thoughtful consideration of power dynamics in eating disorders treatment

${ }^{29}$ See, for example, Victoria Ryan, Helen Malson, Simon Clarke, Gail Anderson and Michael Kohn, 2006 "Discursive constructions of 'eating disorders nursing': An analysis of nurses' accounts of nursing eating disorder patients"; Paula Saukko, 2008 The anorexic self: A personal, political analysis of a diagnostic discourse.

${ }^{30}$ Konstantakopoulos, Tchanturia, Surguladze \& David, 2008, Insight in eating disorders: clinical and cognitive correlates

${ }^{31}$ Roncero, Bellock, Perpina \& Treasure, 2013, "Ego-syntonicity and ego-dystonicity of eating-related intrusive thoughts in patients with eating disorders"
} 
might align well with eating disorders treatment $\frac{32}{2}$ in allowing for a collaborative approach, very few studies have engaged with this framework outside of the purview of eating disorders described as "severe and enduring." This is concerning given that qualitative work has demonstrated the importance of collaboration and engagement with the individual needs of the person seeking treatment in care contexts-perhaps particularly when the person's motivation is seen as being low $\underline{33}$. These perspectives on recovery underscore the need not only for training on "the basics" of eating disorders, but also on the nuanced, complex lived realities of those experiencing eating disorders ${ }^{34}$. Bringing healthcare providers into contact with representations of recovery created by those who have experienced eating disorders and/or their supporters may allow for a fuller picture of the trajectory of an eating disorder from onset to wellbeing. It also presents the possibility of entering into dialogue about what outcomes people might be envisioning when they pursue recovery, moving beyond a linear perspective on an illness-to-wellness trajectory.

\section{Digital Storytelling in Healthcare Education}

Digital storytelling can be used in teaching contexts and to "disrupt dominant narratives and open possibilities" $\underline{35}$ for both story creators and story viewers. In

\footnotetext{
32 Lisa Dawson, Paul Rhodes \& Stephen Touyz 2014b "The recovery model and anorexia nervosa" ${ }^{33}$ Connie Musolino, Megan Warin, Tracey Wade \& Peter Gilchrist 2016 "Developing shared understandings of recovery and care: a qualitative study of women with eating disorders who resist therapeutic care"

${ }^{34}$ Fauzia Mahr, Pantea Farahmand, Edward O. Bixler, Ronald E. Domen, Eileen M. Moser, Tania Nadeem, Rachel L. Levine \& Katherine A. Halmi, 2015 "A national survey of eating disorder training" ${ }^{35}$ Carla Rice \& Ingrid Mündel, 2018 "Story-making as methodology: Disrupting dominant stories through multimedia storytelling", p. 215
} 
healthcare, stories can help to identify what patients/consumers view as important $\frac{36}{6}$ and to enhance therapeutic relationships, presenting the person seeking care as more than just a patient $\frac{37}{3}$. In a study of HCP experiences of viewing digital stories created by young adults and adolescents in a cancer treatment setting, HCPs reported finding stories "powerful, therapeutic, and educational" and discussed how the impacts of viewing the videos were more than simply professional, bringing them into contact with the other roles they play in their lives (for example, that of parent) ${ }^{38}$. The possibilities of digital stories in educational contexts, particularly those with HCP audiences, appear to lie primarily in their ability to promote perspectives on illness as situated in the lived realities and contexts that "patients" bring into their care-which aligns well with recovery model perspectives wherein the individual-in-context is valued and their perspectives are taken into account in their care. Taking these perspectives seriously does not mean abandoning clinical knowledge, but rather integrating clinical and lived experiences to generate possibilities for recoveries that align with varied lived contexts.

In this paper, we present data from one study in the first author's dissertation work with people in recovery from eating disorders and their supporters. The broader study involved interviews $(n=34)$ and digital story creation $(n=5)$ with people in recovery and supporters. Digital stories are short (3-5 $\mathrm{min})$ first person films created by

\footnotetext{
${ }^{36}$ Millender, 2011, "Using stories to bridge cultural disparities, one culture at a time."

${ }^{37}$ Clarke, Hanson \& Ross, 2003 "'Seeing the person behind the patient: Enhancing the care of older people using a biographical approach."

${ }^{38}$ Laing, Moules, Estefan \& Lang, 2017 "Stories take your role away from you": Understanding the impact on health care professionals of viewing digital stories of pediatric and adolescent/young adult oncology patients"
} 
participants to build understanding of lived experiences and shift policies/practices $\underline{39}$. Stories were screened to interprofessional HCPs $(n=22)$ with an aim of understanding how creative representations of recovery might impact those who are, or will one day be, in the position to encounter, treat, and refer those with eating disorders. We asked: How does viewing digital stories about eating disorder recovery created by individuals in recovery and their supporters impact HCPs and their understandings of recovery? We aimed to gain insight into whether patient-generated stories resonate with a subset of practitioners, which could drive further explorations into how to integrate recoverymodel, patient-oriented care into training. This study can be considered a pilot, the results of which can be used to ground future work investigating the relationship between stories of lived experience, $\mathrm{HCP}$ training, and the recovery model.

\section{Methods}

\section{Story Creation}

The study received ethics clearance through the [university] ethics board ([REB\#]). The stories screened were created collaboratively with the first author and were 3-5 minute videos that explored how participants understood recovery in the contexts of their lives. Four participants were in recovery, and one participant was a supporter. Video creation took place in a similar format to that described in our prior work [author citation]: a workshop with people with lived experience including a story circle, collaborative video creation, and screening. All participants from the broader

\footnotetext{
${ }^{39}$ Carla Rice \& Ingrid Mündel, 2018 "Story-making as methodology: Disrupting dominant stories through
} multimedia storytelling" 
study were invited to participate; due to time constraints and distance, we had limited response from the broader group and opted to pursue storywork in two separate workshops (one with three participants, one with two participants) with those who expressed interest and ability to participate. Story creation involved story circles where the first author presented preliminary findings from the broader study, and lead a discussion of participants' perspectives on recovery and visions for their stories. The "co-creation" aspect of the workshop varied depending on participants' proficiency and/or desire to develop proficiency with the editing program Final Cut Pro and Mac computers in general. Participants guided the artistic direction of their films, including image generation/selection and script writing. The first author followed the guidance of participants in assembling the stories, with the exception of one participant who created her story at a distance.

\section{Story Descriptions}

Participants' stories each present a unique relationship to eating disorders and to "recovery." One participant used poems to explore her relationship to self-past, present, and future. She told a non-linear recovery story where she moved forward and backward, feeling the pull of "eating disorder ruts" and re/defining a recovery that opened more possibilities than the narrow perfection presented in, for instance, media depictions of recovery. Another used pen and ink drawings to render the eating disorder as a trap, her visual metaphor for never quite fitting what was expected of her in her family or in society, as an immigrant to Canada. Her story complicated simplistic versions of what eating disorders are and how to recover, as the eating disorder represented her attempt "to be normal" in a world where she was made out to be 
abnormal. Recovery, for her, entailed reconnecting with parts of herself she had previously imagined as "monstrous" or "uncivilized"-a challenging task by any account.

A third participant explored her experiences of living in a body problematized by society and enacting eating disorder behaviours as a way to "feel likeable and in control." She knew that these behaviours hurt her but found when she sought help that providers' "solutions" also did not work for her, including pharmaceuticals rather than listening. Recovery entailed a definition of love and carving out ways of being in relation that were more conducive to wellbeing. Another told how anxiety, OCD, and depression accompanied the eating disorder, which centred around fears of contamination. Assembling recovery for this participant meant working on developing a "not completely conventional" perspective on wellness, where she found a combination of medications and behavioural techniques that allowed her to feel better and more at home in her body and around food.

Finally, one participant, the sister of a person who had experienced an eating disorder, offered a deeply collaborative perspective on recovery; in reflecting on the eating disorder as "an unwelcome guest," she worked up a vision of recovery as continual and unfinished, but certainly achieved collaboratively. Her story in particular spoke to systemic barriers in treatment systems that can impede recovery, including the limited family involvement possible/permissible in some treatment contexts and the cost of additional support, as well as the lack of definition of what a person is aiming for when aiming for "recovery."

Together, the stories present a picture of the heterogeneity of lived perspectives on recovery and the different orientations to desirable forms of help and envisioned 
recoveries. The digital story medium allowed for the stories to be told in the voices of those impacted, as well as for the presentation of non-verbal techniques (e.g. photos and moving images) to "explain" experiences and recoveries. Affect and emotion are brought into the stories through bringing the viewer into contact with the voices and image selections of the teller.

\section{Story Screening}

Digital stories were screened to a convenience sample of 22 HCPs recruited through extended networks within the Canadian healthcare field: 14 medical students, six physicians (non-psychiatric specialty), and two physiotherapists. Stories were screened at HCPs' places of work at three separate screenings: one with a large group primarily made up of medical students, one with a physician, and one with two physiotherapists. Following the completion of the pre-screening questionnaire, the first author offered a brief introduction about the study and the stories; she also allowed time after the screening for questions. The framing provided to HCPs included a broad overview of why and how the stories were created, giving information about the first author's dissertation research on lived experience of and supporter perspectives on recovery including preliminary findings and information about digital stories and the storytelling workshops. Discussions with the HCP audiences also touched on the ways in which the participants' versions at times came into conflict with one another.

Of the HCPs included in the study, 13 had received no training in eating disorders recognition, prevention, treatment, or referral processes. Seven had received some training, and a further two indicated that they were unsure whether or not they had received training. HCPs filled out a qualitative questionnaire about their perceptions 
of recovery prior to and after seeing the videos, as well as their reactions to the videos, what (if anything) they felt they had learned, and who (if anyone) they thought should watch them. The first author coded the questionnaire data and took a thematic approach to analysis, $\underline{40}$ exploring patterns across the dataset (using MAXQDA), and then discussed findings and reflections with the second author.

While the pre-post framing of the questionnaire gestures at an epistemological perspective that signals discrete, measurable change within each individual over time, we considered the data as a collective, illustrating the subtle shifts that may occur when viewers encounter digital stories. Rather than seeking quantifiable change, we explored the emotional and practical resonances of the films as described by the viewers. "Pre" questionnaires might be considered sensitizing devices that alert us to HCPs' existing frames of reference for encountering the films, thickening our understanding of their context. Consistent with Braun and Clarke's (2019) $\frac{41}{4}$ reflection on the importance of theoretical clarity in the use of thematic analysis, it is important to name our theoretical underpinnings which drove analysis. We explore patterns across the dataset in relation to broader social discourses and power structures, taking an approach grounded in critical feminist and embodiment theory that explores the interplay between bodies and environments $\stackrel{42}{2}$ In the thematic analysis approach we followed $\underline{43}$, themes are not

\footnotetext{
40 Virginia Braun \& Victoria Clarke, 2006 "Using thematic analysis in psychology"

41 Virginia Braun \& Victoria Clarke, 2019 "Reflecting on reflexive thematic analysis"

42 Rachelle Chadwick, 2017 "Embodied methodologies: Challenges, reflections and strategies; Carla Rice, 2014

${ }^{43}$ Virginia Braun \& Victoria Clarke, 2006 "What can thematic analysis offer health and wellbeing researchers?"
} 
"diamonds scattered in the sand, waiting to plucked-up by a lucky passer-by" (Braun \& Clarke, 740 ${ }^{44}$; instead, researchers engage with data and interpret always-contextual meaning in relationship to what participants say and the worlds and worldviews around and within both researcher and participant $\frac{45}{}$. Thus, the findings below represent not some objective "truth" about how HCPs conceptualize EDs and recovery, but rather an interpretation using a body-society interactivity theoretical framework of their understandings of and reactions to the videos and the subjects they convey in a moment in time.

\section{Patient and Public Involvement in Research}

In this study, people with lived experience of or supporters of people with eating disorders created their stories collaboratively with the first author. In workshops with these storytellers, we discussed possible audiences for their videos, including HCPs. Consent forms offered options for being contacted prior to screenings; some participants elected to be contacted, whereas others chose to allow the screening of their videos without being contacted first. We consider the stories screened to be "owned by" participants, who determine their use in particular venues for educational, informational, and research purposes.

\section{Results}

\footnotetext{
44 Virginia Braun \& Victoria Clarke, 2016, "(Mis)conceptualising themes, thematic analysis, and other problems with Fugard and Potts' (2015) sample-size tool for thematic analysis", 740

45 Virginia Braun \& Victoria Clarke, 2006 "Using thematic analysis in psychology"; Virginia Braun \& Victoria Clarke, 2016 "(Mis)conceptualising themes, thematic analysis, and other problems with Fugard and Potts' (2015) sample-size tool for thematic analysis"
} 
Overall, though not without exceptions, HCPs found the videos impactful and thought that they contributed to or had the potential to contribute to stigma/stereotype reduction by thickening understandings of diverse experiences of eating disorders and recovery. Most HCPs were at least somewhat familiar with eating disorders and recovery prior to the screenings, despite lacking formal training. Participants' responses following the viewing reflected a nuanced perspective on what eating disorder recovery means, and a strong sense of empathy toward those in recovery and their supporters. HCPs had suggestions for subsequent film creation and screening, including more diverse and longer videos, but generally found them to be a helpful teaching tool in highlighting the complexity of eating disorders and individuality in trajectories of recovery. An overview of the thematic structure we derived from our analysis of questionnaire data is provided in Figure A. Individual thematic maps with quotes are provided in figures B through E (see Appendix). 


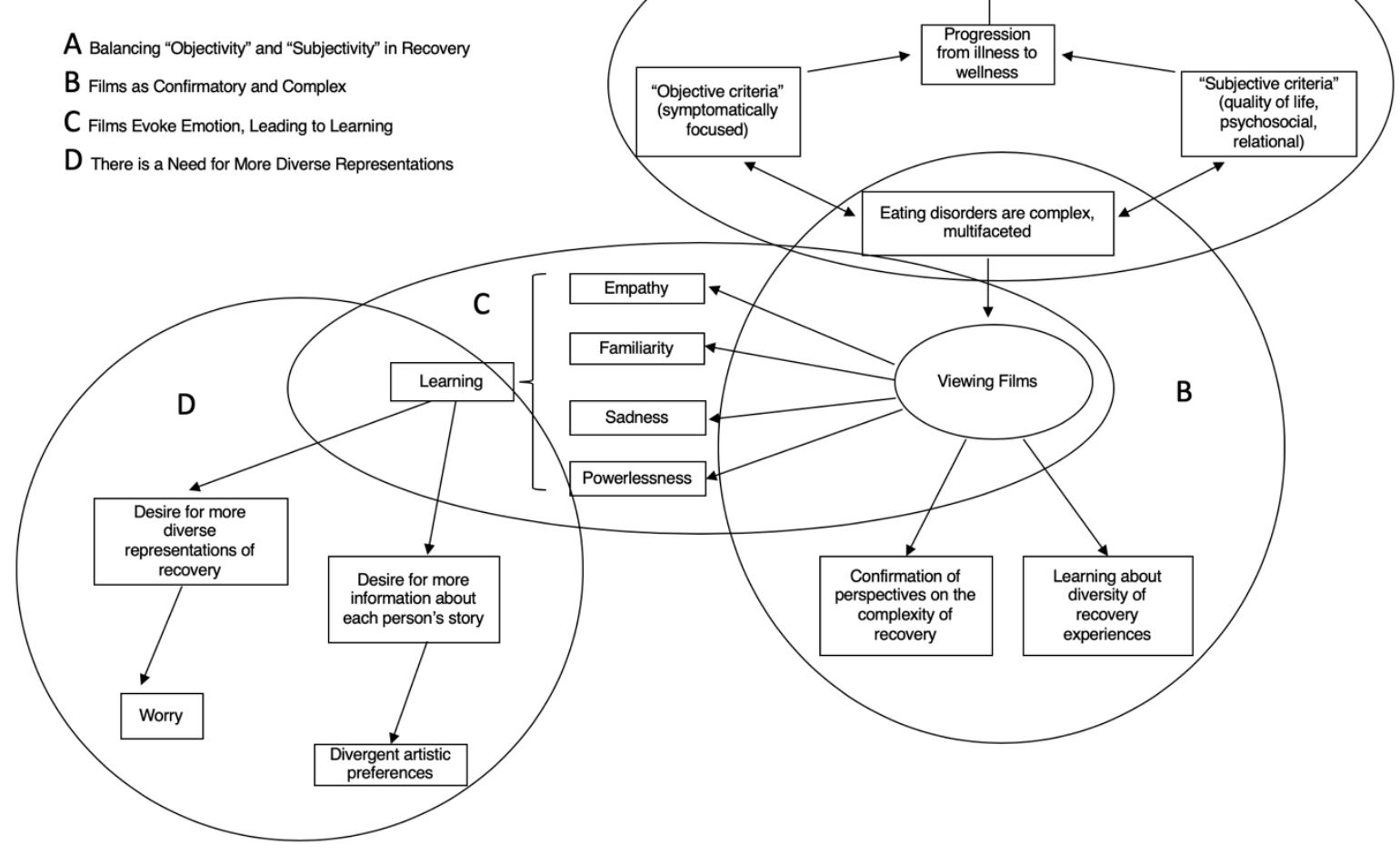

Figure A: Thematic Structure

Balancing "Objectivity" and "Subjectivity" in Recovery

HCP responses entangled understandings of eating disorders and how they come about with perspectives on recovery. In HCP responses, eating disorders were described as complex and multifaceted, even prior to screening. Eating disorders were also positioned as being life-consuming, serious, and challenging mental illnesses. As one HCP described:

I think that an eating disorder encompasses so much more than simply meeting diagnostic criteria. The disorders are insidious in that they co-opt the individual's entire life force, and remain like a backseat driver that won't shut up (HCP 1) 
This pre-screening response extends the experience of an eating disorder beyond a diagnostic understanding ("much more than simply meeting diagnostic criteria") and reflects the ways in which this experience interacts with the embodied experience of the sufferer ("entire life force"), constituting the eating disorder as allconsuming ("won't shut up"). It also reflects a nascent understanding of the body-society interactivity framework in its framing of eating disorders as adversely affecting not only bodies but also entire life-worlds.

Despite the fact that eating disorder were seen as being about "more than simply meeting diagnostic criteria," recovery was generally described in progression or linear terms prior to the screenings. As HCP 2 described, recovery might be seen as "progressing from a state in which one's relationship with food leads to physical and/or psychological harm, to a state in which one's relationship with food can lead to a healthy physical and psychological state." This pre-screening description centres the eating disorder's physical and psychological harms, largely abstracted from the social context in which the recovery is taking place. This perspective was endorsed in HCP responses that highlighted a desire to "fix" the eating disorder and to define recovery at least in part through "objective measures." However, HCPs tended to accompany these statements with a recognition of how each trajectory is unique, and to question the possibility of arriving at a singular "cure" for all, moving toward a perspective that situates symptom remission in the psychosocial lives of those experiencing eating disorders:

I do think there's a need for some objective standards of recovery (e.g., around the severity of interference of behaviours and thoughts with functioning, and maintenance a healthy weight range [on average]), especially given that denial 
and biased perception can be inherent to the illness itself. The challenge is that a definition is only as useful as its ability to accurately represent a concept and be confidently applied, and much of recovery is an internal experience. (HCP 9)

Most HCPs desired a balance between the "necessary elements" of eating disorder recovery and non-universal, contextual elements of recovery. HCPs might cite "medical stabilization" (HCP 16) in the same sentence as they defined eating disorder recovery as "an ongoing journey" also including "healing the thoughts associated with the eating disorder." As such, HCP 16's description evidences the interplay of biomedical and psychosocial aspects of recovery.

\section{Films as Confirmatory and Complex}

HCPs reported that viewing the films either confirmed their suspicions that eating disorders and recovery were diverse and multifaceted, or taught them about this diversity. Sometimes, the recognition of diversity marked a departure from a more textbook definition in the pre-screening data. For example, prior to screening, HCP 3 defined recovery as:

a journey where someone is re-defining their relationship to their body image, weight, food, and societal expectations, with the outward result being that they continually move toward not having an eating disorder anymore.

Following screening, the same HCP noted that:

Eating disorder recovery means many different things and is unique to the individual. It is often related to the individual's story of how they developed disordered eating. Aetiologies and solutions are therefore extremely varied. 
Here there is a shift from a universal or uniform definition toward a varied and individualized one and also in the way the HCP defined the precursors and responses to eating disorders.

The shift was not always so striking; some HCPs reported that viewing the videos did not necessarily change their pre-existing definition of recovery. This was true particularly, though not exclusively, for those who reported either training or significant interactions with people with eating disorders. One physician captured how the videos did not necessarily teach her about recovery, but reconfirmed her commitment to viewing recovery as individual and multifaceted:

Having been a physician to dozens of people (male and female) with eating disorders, I don't believe that I learned from these films. But I am reminded of depth, complexity, struggle/distress and resilience of humans in their journey of life and for those with eating disorders, their journey to recovery, whatever that is for them. (HCP 20)

Further, while she did not note a major shift in the definition of recovery, she added that "what it means must include the person with the ED; every recovery journey is different/unique."

\section{Films Evoke Emotion, Leading to Learning.}

Most HCPs found the stories impactful; part of this impact related to the learningthrough-emotion they experienced during the viewing. Emotions the videos brought up for HCPs included empathy, sadness, familiarity, and powerlessness. Several noted the relatability of the videos, having experienced eating disorders/disordered eating themselves at some point in their lives. HCP 4 reported a mix of empathy, sadness, and 
relatability, writing that the stories evoked "a sense of sadness, empathy, knowing/relation to certain moments." That HCPs self-disclosed their own experiences suggests that it may have been worthwhile to include not only a question about whether HCPs had been trained in eating disorders, but also about whether they had experienced or known someone close who had experienced one, to more completely assess the state of their knowledge and experience. HCP 8 also reflected on their own experiences and how this impacted their viewing:

They invoked a sense of familiarity. I could understand what the individuals were saying as l've suffered from an eating disorder of my own. They also made me feel understood because others have gone through the same experiences. They brought back feelings of sadness because it got me reflecting on how many individuals suffer from an ED and how much their lives are impacted. (HCP 8)

The last sentence of HCP 8's account reflects a general sense of powerlessness reported by several participants upon viewing the films: essentially, they became more acutely aware of the struggles faced by those in recovery and their supporters, but unsure what they could do to help change the situation. HCP 22, for instance, noted that the films evoked "sadness, empathy, frustration for lack of supports"; similarly, HCP 1 noted: "These films evoked empathy in me and a feeling of powerlessness. For although I, as a med student, aspire to "fix" my patients, illness changes them in ways a healer cannot change." These quotes reveal the limitations of viewing stories in the absence of material ability to shift systems or guidance on how to do so.

Despite evoking powerlessness, this emotive character was tied to the value HCPs noted value in the stories, particularly their ability to broaden perspectives on 
what it means to have and recover from an eating disorder. HCP 10 wrote: "I feel like I learned more about what it's actually like for people to go through eating disorders and the process of recovery."

\section{There is a Need for More Diverse Representations.}

Though HCPs reported that they learned about the diversity of eating disorders and recoveries through viewing the videos, several also noted that they would have liked a) more representations of different kinds of eating disorders and/or b) longer or more detailed films. This expansion would have helped them to better understand eating disorders and recovery, and to feel confident that the videos covered the wide range of experiences many reported being aware of.

With respect to the desire for more diverse representations, several HCPs selfdisclosed prior histories of eating disorders or helping loved ones through eating disorders. One HCP noted that her history of a non-anorexic eating disorder made her yearn for more representations of her particular experience: "some disgruntlement at the lack of representation for other EDs (as a non-anorexia ED survivor) and worrying that these stories will be the only stories/types of EDs that people will learn from" (HCP 4). Though the first author had clarified at the beginning of the screening that not all participants had been diagnosed, and not all had experienced anorexia, the stories did not reflect the full heterogeneity and diversity of eating disorders and those who experience them, partly because of their limited number. As such, this HCP encouraged more framing around the videos to ensure that people did not assume that all participants had experienced anorexia. 
HCPs also shared a desire for longer, more detailed films, which is perhaps unsurprising given that the stories were mostly quite short (ranging from a minute and a half to five minutes). HCPs reported interest and curiosity that led them to desire fuller descriptions of the participants' struggles, contexts, and recoveries that would have allowed them to connect more deeply to the stories. As HCP 3 noted:

The films evoked interest from me, as well as understanding of the strength these individuals had. I became more interested in the background contexts of each story and was intrigued at how different they all are. (HCP 3)

Several participants also expressed a preference for more concrete stories over more "artistic" ones, suggesting that they were seeking more instructional stories: "some of the more artistic ones made me want to hear more $-I$ felt that they were opening up but in a way that was difficult to understand without context" (HCP 6). This should be taken in the context of others who found the artistic representations to be emotionally compelling, for instance HCP 8 who noted that "the last video with the drawings was probably my favourite as it allowed me to more closely get acquainted with the author's mindset." Evidently, one type of video will not be desirable for all audiences. However, the desire for longer videos was shared both by those who preferred "concrete" and "artistic" videos. Thus, while the digital stories were a helpful start, a deeper look into the perspectives of people with eating disorders and supporters would have been appealing to this audience. The videos appeared to be a promising conversation starter around eating disorders and recovery but require framing around the diversity of eating disorders and recoveries to achieve their fullest impact. 


\section{Discussion}

Screening digital stories with HCPs revealed relatively open attitudes around what constitutes recovery. The screenings brought HCPs into contact with representations of recovery generated—and voiced—by those in recovery and supporters. Screenings did not offer a perfect solution to learning about eating disorders and recovery; viewings brought up emotions for HCPs, including powerlessness in the face of limited systemic supports for eating disorders, with many noting that they wanted longer films, more diverse representations, and more information about the context of the storytellers. However, screening digital stories with HCPs did offer the opportunity to begin a nuanced conversation about recoveries. They either confirmed or introduced the idea of different recoveries-and different, often winding pathways to recovery-from the first-person perspectives of storytellers. Given that HCPs all identified groups that would make ideal audiences for the videos—ranging from people at risk to the general public to HCPs in training - they saw merit in the videos and their screening. In line with a recovery model orientation, HCPs were open to the aspects of recovery that may include, but go beyond, the idea of symptom remission.

As noted in other areas of healthcare in which digital story screenings have been held $\stackrel{46}{ }, \mathrm{HCPs}$ reflected on the emotional impact of the films and the ways in which they brought them into the experience of the person. This meant challenging the envisioned "role" of the healthcare provider. Here, this challenge also sometimes invoked a sense of powerlessness. We would argue that this may be tied to the expectation that the HCP is

\footnotetext{
${ }^{46}$ E.g. Laing, Moules, Estefan \& Lang, 2017 "Stories take your role away from you": Understanding the impact on health care professionals of viewing digital stories of pediatric and adolescent/young adult oncology patients"
} 
supposed to provide a "cure" for eating disorders, an expectation that is tacitly present in many studies on eating disorder recovery which foreground achievement of a degree of symptom remission prior to being deemed "recovered." Recognition of powerlessness might also provide an entry-point into discussions of power in and beyond treatment, into how social discourses and power structures are specifically implicated in the development of eating disorders of those telling their stories in digital format.

If we explore eating disorders in relation to other fields of study involving brains and bodies, such as disability studies, we might pause to consider how these framings live in relation to the idea or promise of "cure" and even diagnosis itself. Cure-based conceptualizations might be problematized in terms of their blanket-nature assumption that all individuals can be returned to a "normal" state (see Clare, $2017 \underline{47}$ for a nuanced discussion). A genetic and biological framework, increasingly common in the eating disorders world, offers a promise of cure sometime in the unforeseeable future. This framework can generate hope but may also bring about the imperative of following a certain pathway to "normalcy" that may not fit the contexts of people's lives $\stackrel{48}{ }$. While HCPs encountered stories that challenged the linearity of recovery and nuanced cure, it may have been a leap for them to grapple with/figure out how to help people intervene in the wellness- or illness-promoting aspects of their life contexts in addition to imparting technologies of cure (i.e. behavioural change leading to symptom remission) used in biomedical settings. It is also possible that the conflicting perspectives on recovery embodied within the videos made HCPs unsure about when to pursue particular

\footnotetext{
47 Eli Clare, 2017 Brilliant imperfection: Grappling with cure
}

48 Eli Clare, 2017 Brilliant imperfection: Grappling with cure 
treatment approaches and for whom. Perhaps additional follow-up training would help to provide a stronger roadmap for integrating lived-experience centred care into ED treatment and meeting diverse needs in recovery.

The presentation of an introduction that included information about eating disorders and recovery might be considered a limitation insofar as it could be seen as "priming" HCPs for the stories. However, our pedagogical approach to digital storytelling insists that we provide context around the stories as a part of the process of "setting the stage" for encounters with the stories $\frac{49}{}$. No stories enter the world unmediated; people encounter representations of health and illness in relation to broad stereotypes about what a diagnosis or concept means. Since personal stories about various embodiments and health problems risk reproducing stereotypes, we cannot speak to the pedagogical utility of presenting stories on their own, without framing; indeed providing context may be a necessity in the presentation of illness videos to any audience, including HCPs. $\underline{50}$ While our framing identified some of the stereotypes that circulate around eating disorders, including the myth that they only occur in thin, young, white, able-bodied, heterosexual women, a limitation that became a part of our thematic structure was the lack of diversity in the videos. Participants told different stories of eating disorders and recovery, but they were primarily white and young. Future work in this area might be aimed at more deliberate video collaboration with people from a variety of social locations.

\footnotetext{
49 Rice, Carla, Eliza Chandler, Kirsty Liddiard, Jen Rinaldi, \& Elisabeth Harrison, 2018 "Pedagogical possibilities for unruly bodies."; Rice, Carla, Eliza Chandler, Elisabeth Harrison, Kirsty Liddiard, and Manuela Ferrari, 2015 "Project Re• Vision: Disability at the edges of representation."

${ }^{50}$ Carla Rice, Andrea LaMarre, and Roxanne Mykitiuk, 2018 Cripping the ethics of disability arts research.
} 
Another limitation of the study is that we did not screen stories with many HCPs, and the majority were medical students, who may not yet have experiences working directly with patients. On the other hand, medical students may be an ideal audience for the films, providing the opportunity to a) know about the current state of training around eating disorders and b) provide varied perspectives on recovery at a relatively early stage of practice. The medical students who comprised the largest group to whom the films were screened were students at a medical school oriented toward problem-based learning that does not require all students to come from "pre-med" or even sciencebased backgrounds. Thus, it is possible that these students are more inclined to embrace complexity and context and to look at the interaction between the person and their environments. Further, the viewing was voluntary, people with an interest in eating disorders were likely more inclined to come to the screenings.

Despite these limitations, this study might be considered a pilot for approaches to enhancing healthcare professional training around eating disorders using digital stories. In a review of the effectiveness of arts-based interventions for enhancing medical practice in general, Perry, Maffuli, Wilson \& Morrissey (2011) $\underline{51}$ found that the heterogeneity of studies exploring these approaches and vague nature of described findings precluded strong conclusions about the efficacy of such interventions. However, in work stemming from the second author's arts-based research laboratory, we have found that digital storytelling in particular holds promise for shifting healthcare

\footnotetext{
${ }^{51}$ Mark Perry, Nicola Maffuli, Suzy Wilson \& Dylan Morrissey 2011 "The effectiveness of arts-based interventions in medical education: a literature review"
} 
provider views on and relationships to disability [author citation]. Indeed, "arts-based approaches may help improve care by inviting providers to interrogate the complexities of the inter-and intra-subjective and inter- and intra-corporeal-the in-between spaces created in health care interactions" (Viscardis et al., 10) ${ }^{52}$. Relating back to the recovery model of care, engaging with the arts may provide a much-needed opportunity for healthcare providers to explore how they might empower clients to determine their own recovery pathways by bringing complexity into the picture. Particularly in light of the ongoing debate about what constitutes recovery, the time is right to bring complexity into the ways that we think about eating disorders and care if we wish to facilitate caring—and wellness enhancing—encounters for those seeking recovery.

\section{Acknowledgements}

The story-telling work was hosted by the Re $\bullet$ Vision Centre for Art and Social Justice at the University of Guelph. We wish to acknowledge the participants in recovery and supporters for sharing their stories, and the healthcare providers for hearing these stories and sharing their own in turn. We thank the eating disorder scholars and activists whose work has inspired us and continues to drive work towards systems change in the hope that more people will one day feel safe enough to share their stories.

\section{Contributors}

\footnotetext{
52 Katharine Viscardis, Carla Rice, Victoria Pileggi, Angela Underhill, Eliza Chandler, Nadine Changfoot, Phyllis Montgomery \& Roxanne Mykitiuk, 2018 'Difference within and without: Health care providers' engagement with disability arts", 10
} 
AL designed the study with guidance from $\mathrm{CR}$, who was her $\mathrm{PhD}$ advisor. The methods and process for digital story-telling creation were developed under the umbrella of the Re $\bullet$ Vision Centre for Art and Social Justice. AL worked with participants to create stories, developed the screening materials and screened the stories. She transcribed the responses and conducted the primary analysis.

$\mathrm{CR}$ added to the analysis, and the two authors discussed the thematic structure and overall findings. AL wrote the first draft of the manuscript, and CR provided substantive revisions. Both authors worked on paper revisions following review.

\section{Funding}

This study was funded by the Canadian Institutes of Health Research (grant number: Vanier Scholar Doctoral Award 2014-2017) and the Ontario Ministry of Health and Long-Term Care (Ontario Women's Health Scholar Award 2017-2018). AL's dissertation research was generously funded by the Vanier Canada Doctoral Scholarship (CIHR) and subsequently by the Ontario Ministry of Long-Term Care through the Ontario Women's Health. The views expressed in the material are ours and do not necessarily reflect those of the Ministry of Health and Long-Term Care.

\section{References}

Diann M. Ackard, Sara Richter, Amber M. Egan and Catherine L. Cronemeyer. "What does remission tell us about women with eating disorders? Investigating applications of various remission definitions and their associations with quality of life." Journal of Psychosomatic Research, 76, no. 1 (2014): 12-18. 
William A. Anthony. "Recovery from mental illness: The guiding vision of the mental health service system in the 1990s." Psychosocial Rehabilitation Journal 16, no. 4(1993): 12-23.

Rachel Bachner-Melman, Lilac Lev-Ari, Ada H. Zohar and Shay Lee Lev. "Can recovery from an eating disorder be measure? Toward a standardized questionnaire." Frontiers in Psychology, 9 (2018): Article 2456.

Anna M. Bardone-Cone, Rowan A. Hunt \& Hunna J. Watson. "An overview of conceptualizations of eating disorder recovery, recent findings, and future directions" Current Psychiatry Reports, 20, (2019): 79

Anna M. Bardone-Cone. "Examining the match between assessed eating disorder recovery and subjective sense of recovery: Preliminary findings." European Eating Disorders Review, 20 (2012): 246-249.

Anna M. Bardone-Cone, Megan B. Harney, Christine R. Maldonado, C. R., Melissa A. Lawson, D. Paul Robinson, Roma Smith \& Aneesh Tosh. "Defining recovery from an eating disorder: Conceptualization, validation, and examination of psychosocial functioning and psychiatric comorbidity." Behaviour Research and Therapy, 48, no. 3 (2010): 194-202.

Kathleen M. Berg, Dermot J. Hurley, James A. McSherry and Nancy E. Strange. Eating disorders: A patient-centered approach. (2003). Radcliffe Publishing.

Susan Bordo. "Not just "a white girl's thing": The changing face of food and body image problems." In Critical Feminist Approaches to Eating Dis/Orders, edited by Helen Malson \& Maree Burns (Eds.)(pp. 46-59). New York: Routledge, 2009.

Virginia Braun and Victoria Clarke. "Using thematic analysis in psychology." Qualitative Research in Psychology 3, (2006): 77-101.

Virginia Braun and Victoria Clarke. "Reflecting on reflexive thematic analysis" Qualitative Research in Sport, Exercise, and Health 11, no. 4 (2019): 589-597.

Virginia Braun and Victoria Clarke. "(Mis)conceptualising themes, thematic analysis, and other problems with Fugard and Potts' (2015) sample-size tool for thematic 
analysis." International Journal of Social Research Methodology 19, no. 6 (2016): 739-743.

Fary M. Cachelin, Ramona Rebeck, Catherine Veisel and Ruth H. Striegel-Moore. "Barriers to treatment for eating disorders among ethnically diverse women." International Journal of Eating Disorders 30, no. 3 (2001): 269-278.

A.B. Castro and Salem Levesque. "Using digital storytelling to teach public health advocacy" Public Health Nursing, 35, no. 2, 157-164.

Rachelle Chadwick. "Embodied methodologies: Challenges, reflections and strategies. "Qualitative Research 17, no. 1 (2017): 54-74.

Eli Clare. Brilliant imperfection: Grappling with cure. Durham, NC: Duke University Press, 2017.

Amanda Clarke, Elizabeth Jane Hanson and Helen Ross. "Seeing the person behind the patient: Enhancing the care of older people using a biographical approach." Journal of Clinical Nursing, 12 (2003). 697-706

Tom K.J. Craig. "Recovery: say what you mean and mean what you say." Journal of Mental Health 17, no. 2 (2008): 125-128.

Michele A. Crisafulli, Ann Von Holle \& Cynthia Bulik. "Attitudes towards anorexia nervosa: the impact of framing on blame and stigma." International Journal of Eating Disorders 41, no. 4 (2008): 333-9.

Arthur Crisp, Michael G. Gelder, Susannah Rix, Howard I. Meltzer and Olwyn J. Rowlands. "Stigmatisation of people with mental illnesses." The British Journal of Psychiatry 177, no. 1 (2000): 4-7.

Lisa Dawson, Paul Rhodes and Stephen Touyz. "The recovery model and anorexia nervosa"

Australian \& New Zealand Journal of Psychiatry, 48(11)(2014a): 1009-1016.

Lisa Dawson, Paul Rhodes \& Stephen Touz. "Doing the impossible: The process of recovery from chronic anorexia nervosa." Qualitative Health Research, 24(4)(2014b): 494-505. 
Department of Health. Government response to the consultation: "Liberating the NHS:

No decision about me, without me." London: Department of Health, 2012.

Sander de Vos, Andrea LaMarre, Mirjam Radstaak, Charlotte Ariane Bijkerk, Ernst T.

Bohlmeijer \& Gerben J. Westerhof. "Identifying fundamental criteria for eating disorder recovery: a systematic review and qualitative meta-analysis." Journal of Eating Disorders, 5, (2017), article 34.

Michele Easter. "Not all my fault: Genetics, stigma, and personal responsibility for women with eating disorders." Social Science \& Medicine 75, (2012): 1408-1416.

Michele Easter. "Interpreting genetics in the context of eating disorders: Evidence of disease, not diversity." Sociology of Health and IIIness 36, no. 6 (2014): 840-855.

Karin Eli. Between difference and belonging: Configuring self and other in inpatient treatment for eating disorders. PLoS One 9, no. 9 (2014): e105452.

Ellen E. Fitzsimmons \& Anna M. Bardone-Cone. "Differences in coping across stages of recovery from an eating disorder." Internationational Journal of Eating Disorders, 43 (2010): 689-693.

Kim Flottemesch. "Learning through narratives: The impact of digital storytelling on intergenerational relationships. Academy of Educational Leadership Journal, 17, no. 3 (2013): 53-60.

Gary D. Foster, Thomas A. Wadden, Angela P. Makris, Duncan Davidson, Rebecca Swain Sanderson, David B. Allison and Amy Kessler. "Primary care physicians' attitudes about obesity and its treatment." Obesity Research, 11, no. 10 (2003): 1168-1177.

Laura Girz, Adele Lafrance Robinson and Carole Tessier. "Is the next generation of physicians adequately prepared to diagnose and treat eating disorders in children and adolescents?" Eating Disorders 22, no. 5, (2014): 375-85.

Kathryn H. Gordon, Marisol Perez and Thomas E. Joiner. "The impact of racial stereotypes on eating disorder recognition." International Journal of Eating Disorders 32, no. 2 (2002): 219-224. 
Thomas Insel. "Post by Former NIMH Director Thomas Insel: Spotlight on Eating Disorders." (2012) National Institutes of Health. Retrieved from https://www.nimh.nih.gov/about/directors/thomas-insel/blog/2012/spotlight-oneating-disorders.shtml

Rebecca Jones \& Helen Malson. "A critical exploration of lesbian perspectives on eating disorders." Psychology and Sexuality 4, no. 1, (2013): 1-27.

William R. Jones, Saeideh Saeidi and John F. Morgan. "Knowledge and attitudes of psychiatrists towards eating disorders." European Eating Disorders Review 21, no. 1, (2013): 84-88. Doi: https://doi.org/10.1002/erv.2155

Walter H. Kaye, Julie L. Fudge and Martin Paulus. "New insights into symptoms and neurocircuit function of anorexia nervosa." Nature Reviews Neuroscience 10, (2009): 573-584.

Kelly Klump, Jessica L. Suisman, Alexandra S. Burt, Matt McGue and William G. lacono. "Genetic and environmental influences on disordered eating: An adoption study. Journal of Abnormal Psychology 118, no. 4, (2009): 797-805.

G. Konstantakopoulos, G., Kate Tchanturia, Simon A. Surguladze \& A.S. David. Insight in eating disorders: clinical and cognitive correlates. Psychological Medicine, 41, no. 9 (2018):1951-1961.

Hans Kordy, Bruno Machado Kramer, Roland L. Palmer, Hana Papezova, Jacques Pellet, M Pestage Richard and Janet Treasure. "Remission, recovery, relapse, and recurrence in eating disorders:

Conceptualization and illustration of a validation strategy." Journal of Clinical Psychology, 58, (2002): 833-846.

Kiera Korf \& Kimberley Korf-Uzan. "Addressing weight bias and stigma in health care." Visions: BC's Mental Health and Substance Use Journal, 9, no. 4 (2014): 18-19.

Catherine M. Laing, Nancy J. Moules, Andrew Estefan and Mike Lang. "Stories take your role away from you": Understanding the impact on health care professionals of viewing digital stories of pediatric and adolescent/young adult oncology patients" Journal of Pediatric Oncology Nursing, 34, no. 4 (2017): 261-271. 
Andrea LaMarre and Carla Rice. "Normal eating is counter-cultural: Embodied experiences of eating disorder recovery." Journal of Community and Applied Social Psychology, 26, (2016): 136-149.

Jocelyn Lebow, Leslie A. Sim and Lisa N. Kransdorf. Prevalence of a history of overweight and obesity in adolescents with restrictive eating disorders." Journal of Adolescent Health 56, no. 1 (2015): 19-24.

Rebecca Lester. "Ground zero: Ontology, recognition, and the elusiveness of care in American eating disorders treatment." Transcultural Psychiatry 55, no. 4, (2018): 516-533

Fauzia Mahr, Pantea Farahmand, Edward O. Bixler, Ronald E. Domen, Eileen M. Moser, Tania Nadeem, Rachel L. Levine and Katherine A. Halmi. "A national survey of eating disorder training." International Journal of Eating Disorders 48, no. 4 (2015): 443-445.

Eugenia Millender. "Using stories to bridge cultural disparities, one culture at a time." Journal of Continuing Education in Nursing, 42, no. 1 (2010): 37-42

Connie Musolino, Megan Warin, Tracey Wade and Peter Gilchrist. "Developing shared understandings of recovery and care: A qualitative study of women with eating disorders who resist therapeutic care." Journal of Eating Disorders 4, no. 36 (2016): 1-10.

Greta Noordenbos and Aike Seubring. "Criteria for recovery from eating disorders according to patients and therapists." Eating Disorders 14, no. 1 (2006): 41-54.

Greta Noordenbos. "Which criteria for recovery are relevant according to eating disorder patients and therapists?" Eating Disorders 19, no. 5 (2011a): 441-451. doi: 10.1080/10640266.2011.618738

Greta Noordenbos. "When have eating disordered patients recovered and what do the DSM-IV criteria tell about recovery?" Eating Disorders 19, no. 3 (2011b): 234245. 
Mark Perry, Nicola Maffuli, Suzy Wilson and Dylan Morrissey. "The effectiveness of arts-based interventions in medical education: a literature review." Medical Education 45, no. 2 (2011): 141-148.

Jennifer Poole. Behind the rhetoric: Mental health recovery in Ontario. Winnipeg, MA: Fernwood Publishing, 2011.

Rhys Price-Robertson, Lenore Manderson and Cameron Duff. "Mental ill health, recovery and the family assemblage." Cultural Medicine and Psychiatry 41, no. 3, (2017): 407-430.

Carla Rice. Becoming women: The embodied self in image culture. Toronto, ON: University of Toronto Press, 2014.

Carla Rice and Ingrid Mündel. "Story-making as methodology: Disrupting dominant stories through multimedia storytelling." Canadian Review of Sociology 55, no. 2 (2018): 211-231.

Carla Rice, Eliza Chandler, Kirsty Liddiard, Jen Rinaldi and Elisabeth Harrison. "Pedagogical possibilities for unruly bodies." Gender and Education 30, no. 5 (2018): 663-682.

Carla Rice, Eliza Chandler, Elisabeth Harrison, Kirsty Liddiard and Manuela Ferrari. "Project Re• Vision: Disability at the edges of representation." Disability \& Society 30, no. 4 (2015): 513-527.

Carla Rice, Andrea LaMarre, and Roxanne Mykitiuk, "Cripping the ethics of disability arts research." Handbook of ethics in critical research: Stories from the field Ed by Catriona Macleod, J. Marx, P. Mnyaka, G. Treharne (pp 257-272). London: Palgrave, 2018.

James P. Roehrig and Carmen P. McLean. "A comparison of stigma toward eating disorders versus depression." International Journal of Eating Disorders 43, 7 (2010): 671-4.

Kelly A. Romano \& Deborah Ebener. "Disparities in psychological well-being based on subjective and objective eating disorder recovery statuses, and recovery status 
concordance" Eating Disorders: The Journal of Treatment \& Prevention, 27, no. 1, (2019): 82-99.

Maria Roncero, Amparo Belloch, Conxa Perpina and Janet Treasure. "Ego-syntonicity and ego-dystonicity of eating-related intrusive thoughts in patients with eating disorders. Psychiatry Research, 208 (2013): 67-73.

Victoria Ryan, Helen Malson, Simon Clarke, Gail Anderson and Michael Kohn. 'Discursive constructions of 'eating disorders nursing': An analysis of nurses' accounts of nursing eating disorder patients." European Eating Disorders Review, 14 (2006): 125-135. doi: 10.1002/erv.666

Paula Saukko. The anorexic self: A personal, political analysis of a diagnostic discourse. New York, NY: SUNY Press, 2008.

Geoff Shepherd, Jed Boardman \& Maurice Burns. Implementing Recovery: a methodology for organisational change. London, UK: Sainsbury Centre for Mental Health, 2010.

Sarmila Sinha and Nasir Warfa. "Treatment of eating disorders among ethnic minorities in Western settings: A systematic review." Psychiatria Danubina 25, Suppl. 2 (2013): 295-299.

Margarita C.T. Slof-Op't Landt, Alexandra E. Dingemans, Jésus de la Torre Y Rivas \& Eric F. van Furth. "Self-assessment of eating disorder recovery: Absence of eating disorder psychopathology is not essential." International Journal of Eating Disorders Volume, 52, no.8 (2019): 956-961

Lynda Tait and Helen Lester. "Encouraging user involvement in mental health services." Advances in Psychiatric Treatment 11, no. 3 (2005): 168-175.

Nancy Tomes. "The patient as a policy factor: A historical case study of the consumer/survivor movement in mental health." Health Affairs 25, no. 3 (2006): 720-9.

Johan Vanderlinden, Hélène Buis, Guido Pieters and Michel Probst. "Which elements in the treatment of eating disorders are necessary 'ingredients' in the recovery 
process? A comparison between the patient's and therapist's view." European Eating Disorders Review 15, no. 5 (2007): 357-365.

Katharine Viscardis, Carla Rice, Victoria Pileggi, Angela Underhill, Eliza Chandler, Nadine Changfoot, Phyllis Montgomery and Roxanne Mykitiuk. "Difference within and without: Health care providers' engagement with disability arts." Qualitative Health Research E-pub ahead of print. (2018) 1-12.

Tracy D. Wade \& James Lock. "Developing consensus on the definition of remission and recovery for research." International Journal of Eating Disorders, (2019) online early view.

Meris Williams \& Pierre Leichner. "More training needed in eating disorders: A time cohort comparison study of Canadian psychiatry residents." Eating Disorders 14, no. 4 (2006): 323-334. 


\section{Appendix: Thematic Structure Diagrams}

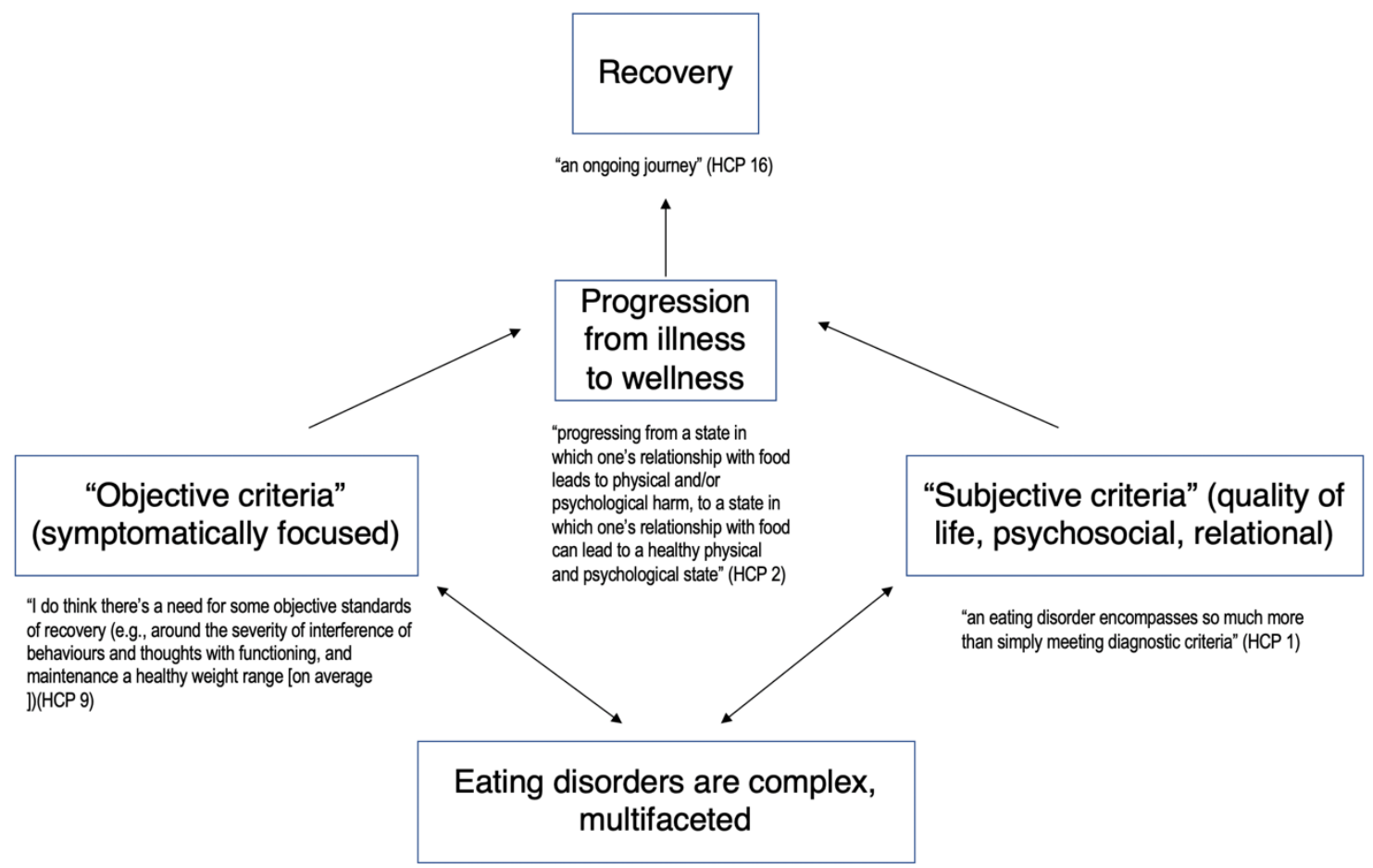

Figure B: Balancing "Objectivity" and "Subjectivity" in Recovery 


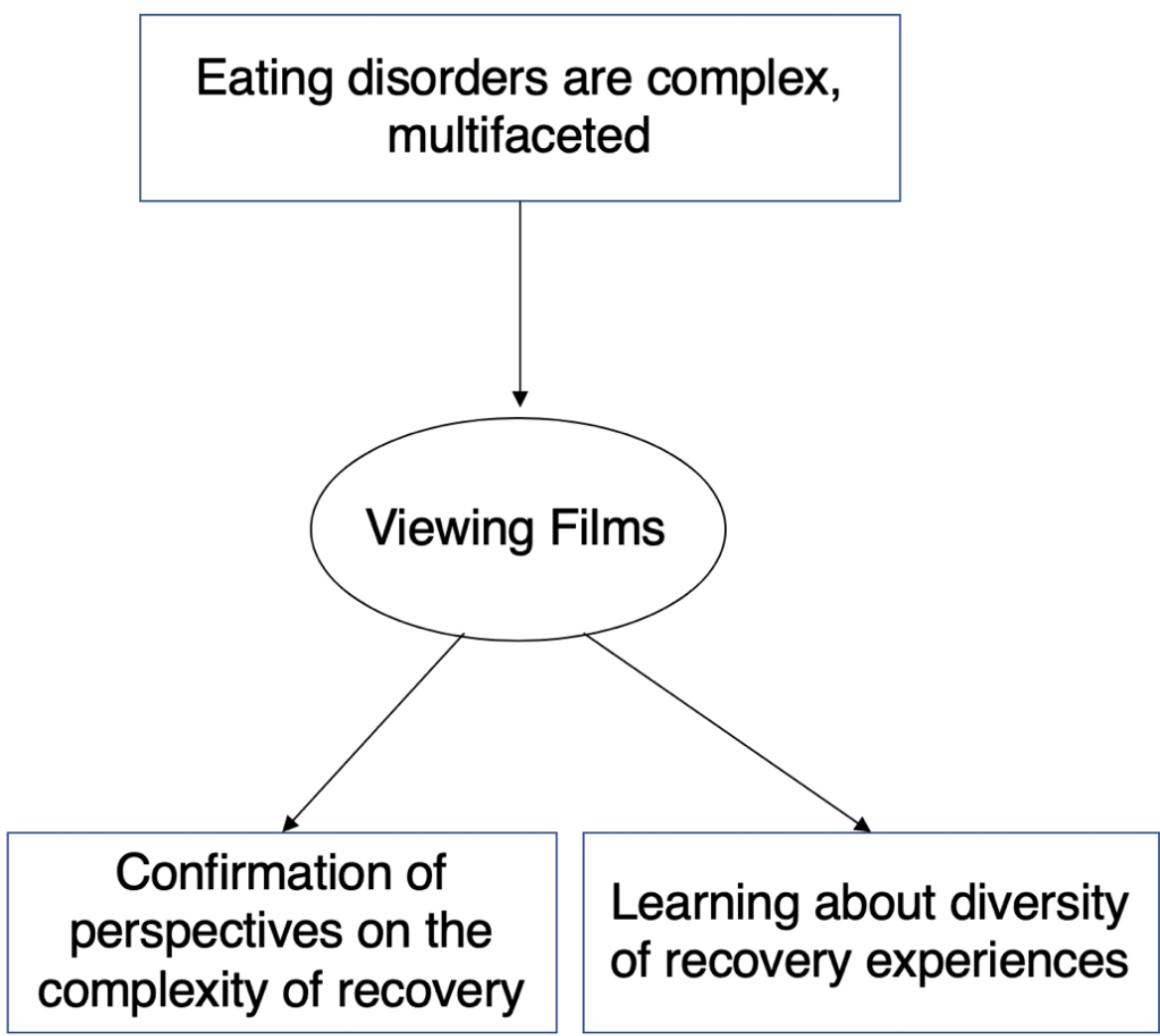

"Having been a physician to dozens of people (male and female) with eating disorders, I don't believe that I learned from these films. But I am reminded of depth, complexity, struggle/distress and resilience of humans in their journey of life and for those with eating disorders, their journey to recovery, whatever that is for them." (HCP 20)

"Eating disorder recovery means many different things and is unique to the individual. It is often related to the individual's story of how they developed disordered eating. Aetiologies and solutions are therefore extremely varied." (HCP 3 )

Figure C: Films as Confirmatory and Complex 


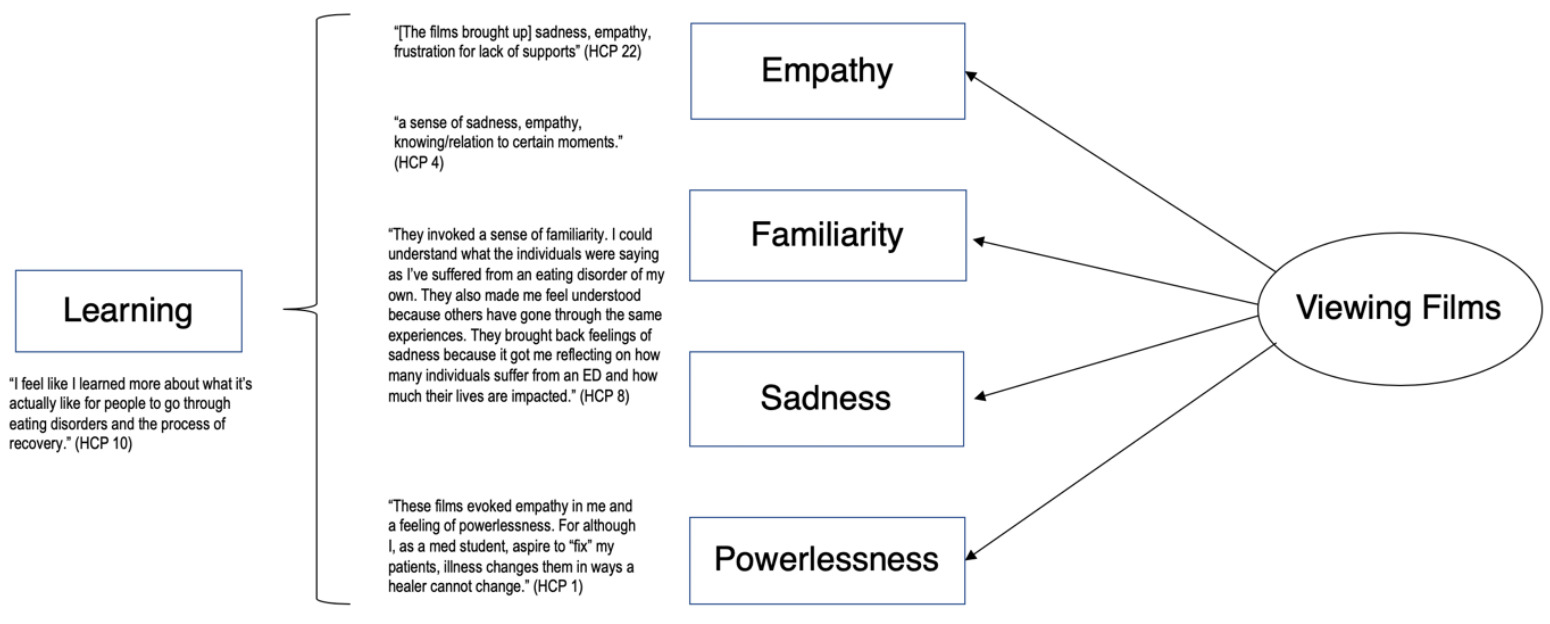

Figure D: Films Evoke Emotion, Leading to Learning 


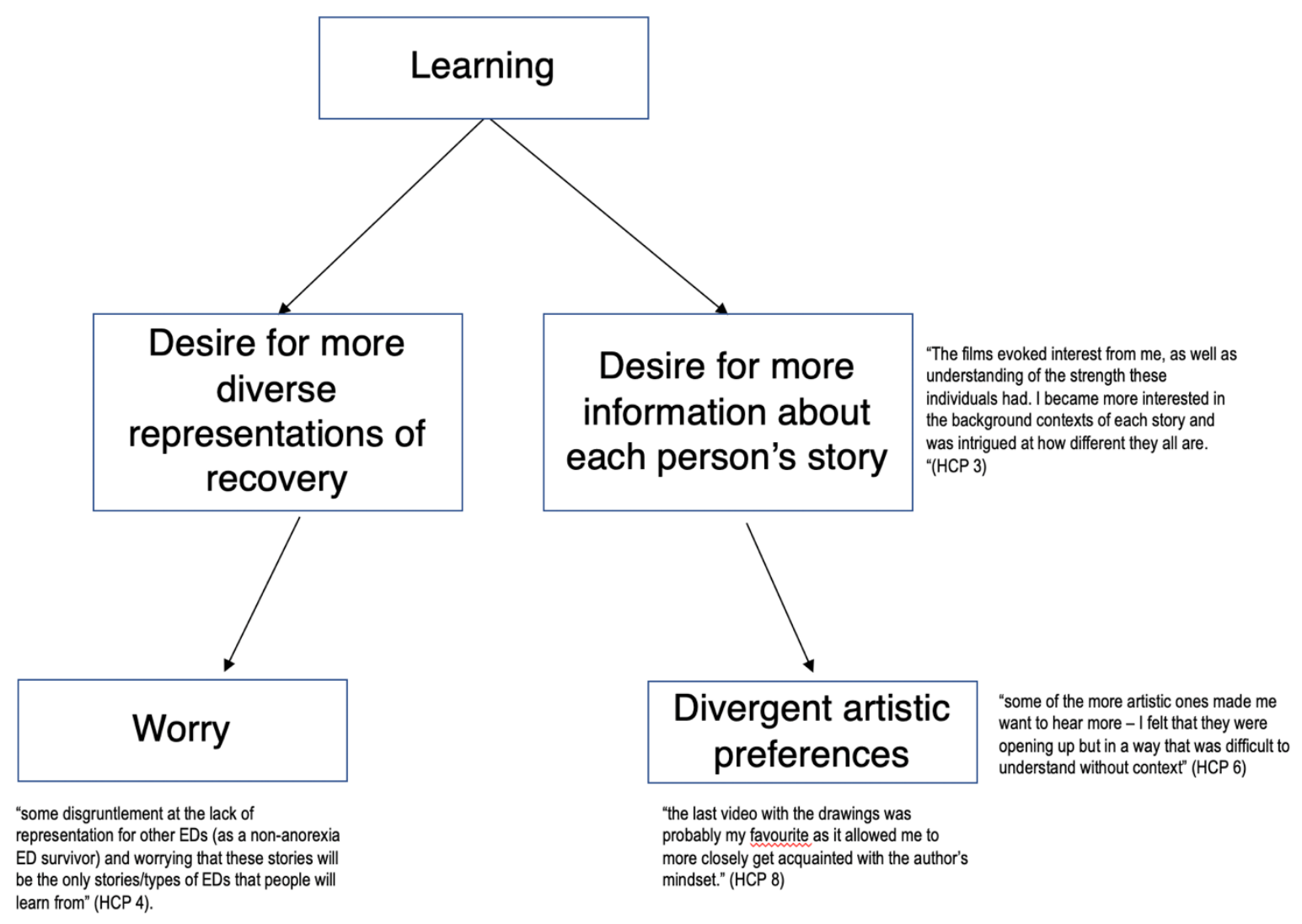

Figure E: There is a Need for More Diverse Representations 